\title{
Primary auditory cortex regulates threat memory specificity
}

\author{
Mattis B. Wigestrand, ${ }^{1,2}$ Hillary C. Schiff, ${ }^{1}$ Marianne Fyhn, ${ }^{2}$ Joseph E. LeDoux, ${ }^{1,3}$ \\ and Robert M. Sears ${ }^{1,3}$ \\ ${ }^{1}$ Center for Neuroscience, New York University, New York, New York 10003, USA; ${ }^{2}$ Department of Molecular Biosciences, University of \\ Oslo, 0371 Oslo, Norway; ${ }^{3}$ Emotional Brain Institute, Nathan Kline Institute for Psychiatric Research, Orangeburg, New York 10962, \\ USA
}

\begin{abstract}
Distinguishing threatening from nonthreatening stimuli is essential for survival and stimulus generalization is a hallmark of anxiety disorders. While auditory threat learning produces long-lasting plasticity in primary auditory cortex (Aul), it is not clear whether such Aul plasticity regulates memory specificity or generalization. We used muscimol infusions in rats to show that discriminatory threat learning requires Aul activity specifically during memory acquisition and retrieval, but not during consolidation. Memory specificity was similarly disrupted by infusion of $\mathrm{PKM} \zeta$ inhibitor peptide (ZIP) during memory storage. Our findings show that Aul is required at critical memory phases and suggest that Aul plasticity enables stimulus discrimination.
\end{abstract}

[Supplemental material is available for this article.]

Two parallel neural pathways convey auditory information to the lateral nucleus of the amygdala where associative plasticity occurs during Pavlovian threat conditioning. Either of these pathways, the thalamo-amygdala and the thalalamo-cortico-amygdala pathway, can independently support auditory threat (fear) learning (Romanski and LeDoux 1992b; Campeau and Davis 1995; Antunes and Moita 2010), but the conditions that engage the cortical route and its functional role in threat memory are poorly understood (Grosso et al. 2015).

In particular, it has been claimed that the primary auditory cortex (Au1) is dispensable for threat memory since animals with auditory cortex lesions are able to acquire and retrieve auditory threat memories that involve a single tone CS (Romanski and LeDoux 1992a,b; Sacco and Sacchetti 2010). However, multiple electrophysiological studies show that threat conditioning produces specific and long-lasting plasticity of the conditioned stimulus (CS) responses in Au1 (Bakin and Weinberger 1990; Edeline and Weinberger 1993; Gao and Suga 2000). Further, recent studies that used a differential threat conditioning protocol found that inhibiting the thalamo-cortico-amygdala pathway reduced the ability to discriminate sounds paired with footshock (CS+) from sounds which were never reinforced (CS -) (Antunes and Moita 2010; Aizenberg et al. 2015). These findings suggest that Au1 activity may be required to distinguish between CS + and CS - , but it is not clear whether Au1 is a passive relay or a site of plasticity. In support of a functional role for Au1 plasticity, Letzkus et al. (2011) identified an Au1 microcircuit that allows convergence of auditory CS with unconditioned stimulus (US) information in Au1, thus possibly gating associative CS-US plasticity within Au1 during threat memory acquisition.

If plasticity within Au1 is required for accurate threat learning, then distinct predictions can be made about the effects of Au1 manipulations on the different phases of threat memory processing-acquisition, memory storage, and retrieval. Thus, block-

\section{Corresponding author: m.b.wigestrand@ibv.uio.no}

Article is online at http://www.learnmem.org/cgi/doi/10.1101//m.044362. 116. ing synaptic activity in Au1 during conditioning should block acquisition, and disrupting established plasticity mechanisms in Au1 during memory storage should disrupt expression of discriminatory threat memory. Similarly, blocking synaptic activity in Au1 during memory retrieval should disrupt the expression of discriminatory threat memory. To explore the role of Au1 in threat memory specificity, we address these predictions with reversible muscimol inactivation of Au1 at different phases of threat memory processing. We further examine the behavioral significance of memory storage mechanisms in Au1 through disruption of the protein kinase $\mathrm{M}$, zeta (PKM $\zeta$ ) pathway.

As a starting point, we aimed to assess the experimental conditions that recruit the Au1 during threat conditioning. Although animals with permanent lesions in Au1 show normal threat conditioning to a single tone CS (Romanski and LeDoux 1992a,b; Sacco and Sacchetti 2010), brain lesions lack temporal precision and interpretations may be confounded by compensatory mechanisms. To control for this issue, we examined whether acute silencing of $\mathrm{Au} 1$ with infusions of the $\mathrm{GABA}_{\mathrm{A}}$ agonist muscimol would similarly fail to influence threat conditioning to a single auditory CS (a series of $9.3 \mathrm{kHz}$ tone pips). Muscimol or vehicle was infused prior to the training session (consisting of 3 CSs which coterminated with a footshock; see Supplemental Methods for details) and CS-evoked freezing was examined $24 \mathrm{~h}$ later under drugfree conditions in a long-term memory test (Fig. 1A). Consistent with lesion studies, we found no significant differences in freezing in rats that received pretraining muscimol compared with vehicle $\left(t_{(8)}=0.89, P=0.40\right)$, confirming that Au1 activity is not required for the formation of threat memories that involve a single tone CS (Fig. 1D). To confirm that our infusions were targeting the Au1 specifically, we estimated the anatomical spread of muscimol by

(C) 2016 Wigestrand et al. This article is distributed exclusively by Cold Spring Harbor Laboratory Press for the first 12 months after the full-issue publication date (see http://learnmem.cshlp.org/site/misc/terms.xhtml). After 12 months, it is available under a Creative Commons License (AttributionNonCommercial 4.0 International), as described at http://creativecommons. org/licenses/by-nc/4.0/. 
A

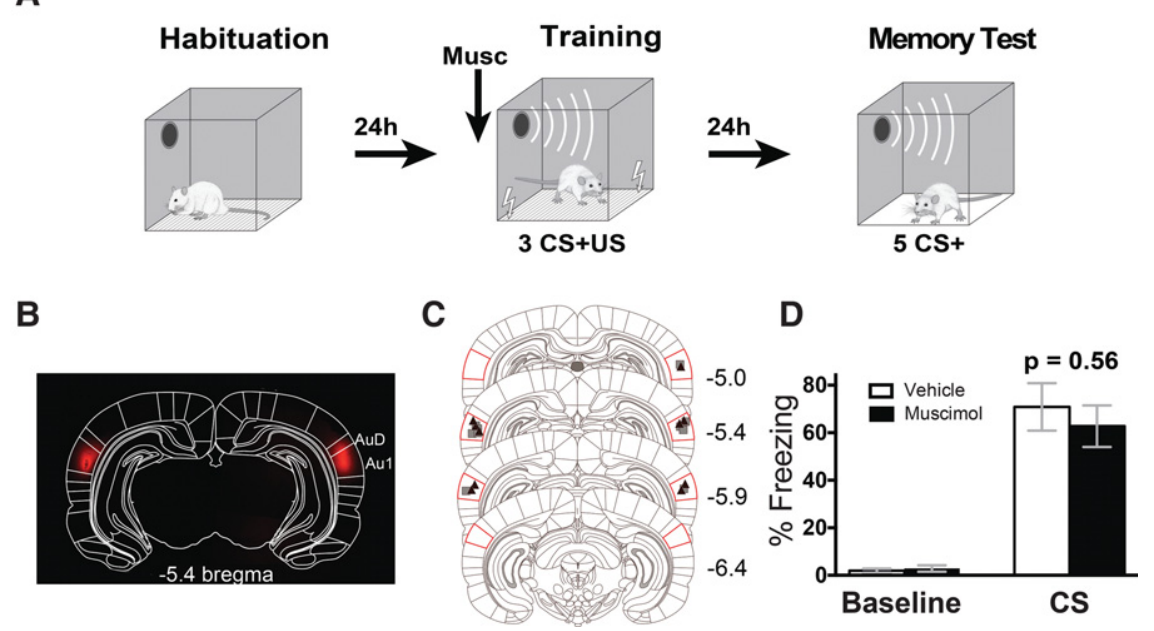

Figure 1. Pretraining muscimol in Au1 does not affect single tone threat conditioning. (A) Schematic outlining the conditioning protocol. (B) Representative spread of fluorescent muscimol after infusion in Au1 fitted to the Paxinos and Watson 6th ed. rat brain atlas. (Paxinos and Watson 2007). (C) Sites of vehicle ( $\mathbf{\square})$ and muscimol $(\boldsymbol{\Lambda})$ cannula hits for single tone threat conditioning experiment. Images modified and $\mathrm{A} / \mathrm{P}$ values from Paxinos and Watson 6th ed. Red lines show the position of Au1. (D) Pretraining muscimol in Au1 does not affect memory formation as assessed by freezing to the tone during the memory test (vehicle, $n=5$; muscimol, $n=5$ ). AuD, dorsal secondary auditory cortex; Au1, primary auditory cortex. Bars represent \pm SEM.

inspecting cannula tracks and by infusing fluorescently labeled muscimol in a subset of animals. Histological analysis revealed cannula hits within Au1 (Figs. 1C, 2B-D, 3B) and muscimol fluorescence specifically in the primary auditory cortex with some spread to the surrounding dorsal, secondary auditory cortex (Fig. 1B).

To explore the experimental conditions that engage Au1 during threat learning, we switched to a threat conditioning assay that requires animals to distinguish threatening and neutral stimuli. In this behavioral assay, rats were trained to discriminate between two pure tones of distinct frequencies: the $\mathrm{CS}+$, a series of $9.3 \mathrm{kHz}$ tone pips, was paired three times with a footshock, while the CS-, a series of $2 \mathrm{kHz}$ tone pips, was presented the same number of times, but never paired with footshock (Fig. 2A). As expected, unmanipulated rats were able to robustly discriminate $\mathrm{CS}+$ and $\mathrm{CS}-$, evidenced by higher freezing to CS + compared with CS - during the memory test $\left(50 \pm 3 \%\right.$ vs $28 \pm 5 \%$ freezing; $t_{(10)}=$ 4.09, $P=0.002$ ).

To test whether Au1 activity was required during the acquisition phase of the discriminatory assay, we infused muscimol or vehicle into Au1 prior to the training session. A two-way ANOVA revealed a significant main effect for CS type $\left(F_{(1,15)}=31.46, P<0.0001\right)$, no significant main effect for drug $\left(F_{(1,15)}=\right.$ $0.09, P=0.77$, and a significant CS type $\times$ drug interaction $F_{(1,15)}=15.00$, $P=0.002)$. A Sidak post hoc test revealed that while vehicle rats showed higher freezing to CS+ than CS- during the memory test $(P<0.0001)$, rats that received pretraining muscimol infusions failed to discriminate between $\mathrm{CS}+$ and CS $-(P=0.40)$. Thus, inactivation of Au1 during memory acquisition resulted in a generalized threat memory with similar freezing to $\mathrm{CS}+$ and $\mathrm{CS}-$ (Fig. 2E; Supplemental Figs. S1, S2).

Given that muscimol, when infused prior to training, is likely still present in Au1 during the consolidation phase, the pretraining muscimol effect could be due to manipulation of the acquisition phase and/or the consolidation phase of memory formation. To rule out potential drug effects during the consolidation phase, we infused muscimol into Au1 immediately after the training session so that the drug would be active during consolidation, but not training. A two-way ANOVA revealed a significant main effect for CS type $\left(F_{(1,9)}=37.50\right.$, $P=0.0002)$, no significant main effect for drug $\left(F_{(1,9)}=0.27, P=0.62\right)$, and no significant CS type $\times$ drug interaction $\left(F_{(1,9)}=0.82, P=0.39\right)$, indicating that discriminatory threat learning was not significantly influenced by disrupting Au1 activity during the consolidation phase (Fig. 2F).

We next asked if Au1 activity is required for the retrieval of a discriminatory threat memory. In this experiment, rats were trained drug-free and infused with muscimol immediately prior

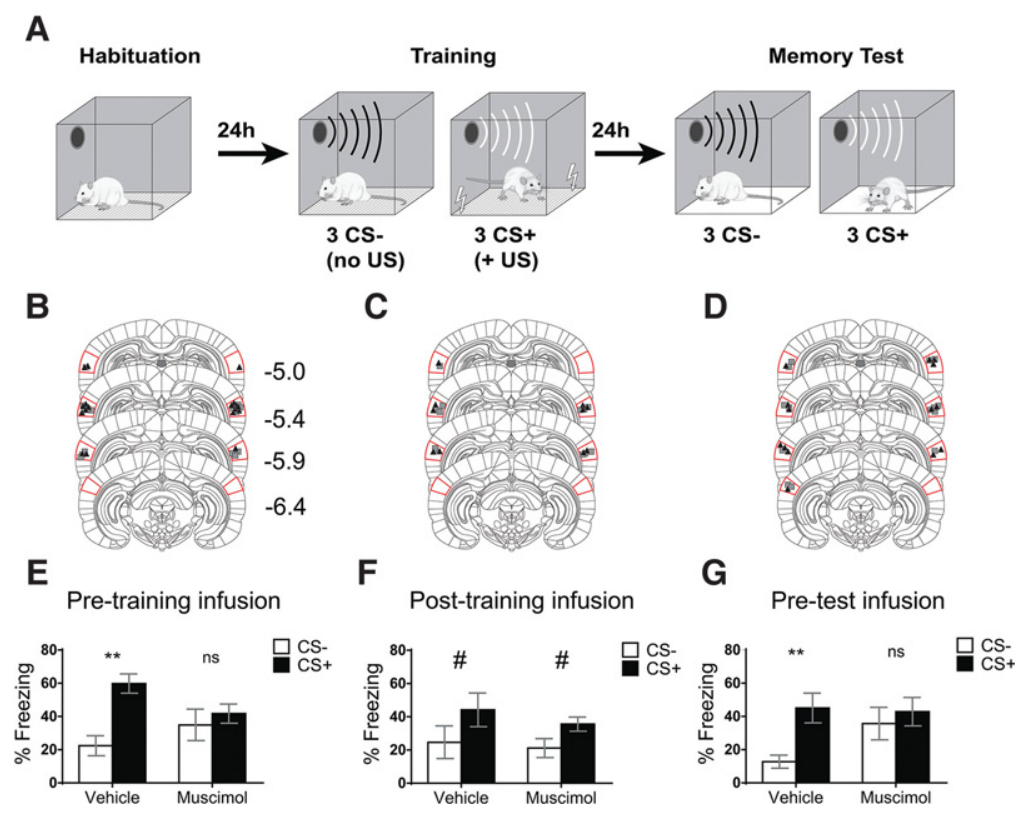

Figure 2. Pretraining and pretest infusion of muscimol in Au1 disrupt discriminatory threat condtioning. (A) Schematic outlining the discriminatory threat conditioning protocol. $(B-D)$. Sites of vehicle ( $\square)$ and muscimol $(\mathbf{\Lambda})$ infusions for discriminatory threat conditioning experiments. Images modified and $\mathrm{A} / \mathrm{P}$ values from Paxinos and Watson 6th ed. Red lines show the position of Au1. (E) Pretraining muscimol infusion in Au1 impairs discrimination of paired (CS + ) and unpaired (CS - ) tones (vehicle, $n=8$; muscimol, $\left.n=9 ;\left(^{* *}\right) P<0.01\right)$. (F) Post-training muscimol infusion in primary auditory cortex does not affect discriminatory threat conditioning (vehicle, $n=6$; muscimol, $n=5$; (\#) significant main effect for CS type, no significant main effect for drug, and no significant CS type $\times$ drug interaction). (G) Pretest infusion of muscimol in Au1 impairs auditory discrimination during the memory test (vehicle, $n=7$; muscimol, $n=7$ ). Au1, primary auditory cortex. Bars represent \pm SEM. 
A

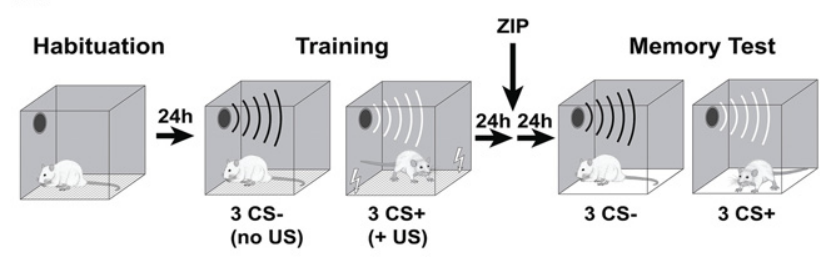

B

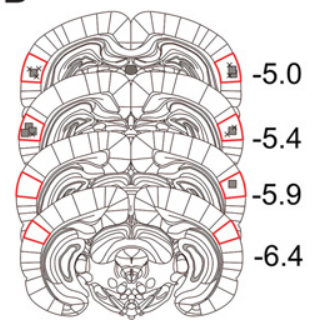

C

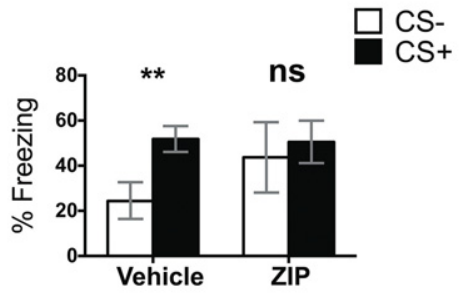

Figure 3. Infusion of ZIP $24 \mathrm{~h}$ after discriminatory threat conditioning impairs discriminatory threat memory. (A) Schematic outlining the dis-

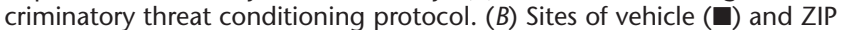
$(X)$ infusions for discriminatory threat conditioning experiments. Images modified and A/P values from Paxinos and Watson 6th ed. Red lines show the position of Au1. (C) Post-training ZIP infusion in Au1 disrupts memory for discriminatory threat conditioning (vehicle, $n=4$; muscimol, $\left.n=4 ;\left({ }^{* *}\right) P<0.01\right)$. Au1, primary auditory cortex. Bars represent \pm SEM.

to the long-term memory test $24 \mathrm{~h}$ later. A two-way ANOVA revealed a significant main effect for CS type $\left(F_{(1,12)}=11.51\right.$, $P=0.005$, no significant main effect for drug $\left(F_{(1,12)}=1.09\right.$, $P=0.32)$ and a significant interaction $\left(F_{(1,12)}=4.66, P=0.05\right)$. A Sidak post hoc test revealed that while vehicle rats showed higher freezing to $\mathrm{CS}+$ than $\mathrm{CS}-$ during the memory test $(P=$ $0.004)$, animals that received pretest muscimol infusions failed to discriminate between $\mathrm{CS}+$ and $\mathrm{CS}-(P=0.64)$. Thus, inactivation of Au1 during retrieval resulted in generalized threat memory expression with equivalent freezing to $\mathrm{CS}+$ and CS - (Fig. 2G).

To assess more directly whether discriminatory threat learning requires plasticity and memory storage mechanisms in Au1, we next infused ZIP, which reverses established long-term synaptic potentiation (Pastalkova et al. 2006; Volk et al. 2013) and disrupts cortical memory (Shema et al. 2007; Sacco and Sacchetti 2010; Cooke et al. 2015). We trained rats in a drug-free state and waited $24 \mathrm{~h}$ before infusing ZIP or vehicle into Au1. After ZIP infusion, we also gave the rats a $24 \mathrm{~h}$ wash-out period to clear residual ZIP in Au1 before the memory test (Fig. 3A). A two-way ANOVA revealed a significant main effect for CS type $\left(F_{(1,6)}=\right.$ 22.78, $P=0.003)$, no main effect for $\operatorname{drug}\left(F_{(1,6)}=0.39, P=0.55\right)$ and a significant interaction $\left(F_{(1,6)}=8.36, P=0.03\right)$. A Sidak post hoc test revealed that while rats treated with vehicle showed higher freezing to CS + than CS - during the memory test $(P=$ 0.003), rats that received ZIP infusions failed to discriminate between $\mathrm{CS}+$ and $\mathrm{CS}-(P=0.41)$. Thus, reversing plasticity with ZIP after learning had occurred resulted in a generalized threat memory with similar freezing to CS+ and CS - (Fig. 3C).

Previous work has shown that threat conditioning accentuates and sharpens CS-elicited neural responses in Au1 (Weinberger 2015), but it is not clear whether this plasticity is required to discriminate between threatening and neutral stimuli (Ohl and Scheich 2004). Our findings with ZIP infusions indicate that local Au1 plasticity is indeed required for discriminatory threat learning. Most likely, Au1 plasticity is initiated during acquisition as synaptic activity in Au1 was required during acquisi- tion, and it also must be intact during retrieval to discriminate between $\mathrm{CS}+$ and $\mathrm{CS}-$. We found that post-training inhibition of Au1 activity did not affect memory consolidation, which may depend instead on intracellular signaling (Maren et al. 1996; Wilensky et al. 1999; Schafe and LeDoux 2000). Previous studies show that infusion of muscimol or ZIP into the auditory cortex does not influence locomotion or anxiety-like behavior, indicating that our results are not confounded by such nonspecific effects (Sacco and Sacchetti 2010; Masini et al. 2012; Znamenskiy and Zador 2013; Xiong et al. 2015). Further, in the single tone threat conditioning experiment (Fig. 1D), we found that pretraining muscimol did not influence CS+ freezing during the memory test, indicating that the lack of discrimination in Figure 2E is not just a reduction in responding to the CS+. The lack of effect after muscimol infusions in our single tone threat conditioning experiment is also consistent with the established circuit model where the direct thalamo-amygdala pathway can independently provide auditory information for the formation of a generalized threat memory (LeDoux 2000).

In a study by Armony et al. (1997), rats with Au1 lesions showed normal stimulus generalization after auditory threat conditioning to a single tone. A possible explanation for the discrepant findings between this study and the current studies is that we used a discriminatory two tone protocol, which may increase dependency on Au1 as suggested by several previous investigations (Jarrell et al. 1987; Teich et al. 1988; Antunes and Moita 2010; Letzkus et al. 2011; Aizenberg et al. 2015). It is often argued that the auditory cortex is specifically involved in threat learning that involves complex and naturalistic auditory stimuli, like frequency-modulated sweeps or tone pips (Ohl et al. 1999; LeDoux 2000; Letzkus et al. 2011). In our study we used tone pips, which has been shown to increase perirhinal cortex involvement in auditory threat memory, possibly because it requires the animal to bind stimulus elements together into a unitary representation (Kholodar-Smith et al. 2008). The use of tone pips in our study could have emphasized the role of Au1 in discriminatory threat learning.

Au1 and other parts of auditory cortex may have distinct roles in threat memory processing. Recent studies show that retrieval of single tone threat memory requires the secondary auditory cortex at remote time points, but not at recent time points (Boatman and Kim 2006; Sacco and Sacchetti 2010; Kwon et al. 2012; Grosso et al. 2015). Understanding the time-dependent manner in which cortical sub-regions, like Au1 and the secondary auditory cortex, interact should provide a step forward in our understanding of cortical memory processing.

Generalization of defensive responses, even in the presence of neutral stimuli, is a hallmark of post-traumatic stress disorder (PTSD) and other anxiety disorders. These generalized fear responses correlate with hyperactivity in the amygdala (Milad et al. 2006, 2009; Ghosh and Chattarji 2015), and may involve disruptions in inhibitory mechanisms for reactions to nonthreatening stimuli (Jovanovic et al. 2010a,b, 2013; Norrholm et al. 2011; Bowers and Ressler 2015). Our study supports the idea that Au1 is involved in such inhibitory control, and that appropriate reactions to threats and neutral stimuli require cortical inputs to the amygdala. In the case of Au1 dysfunction, which leaves only the thalamic auditory inputs to the amygdala, generalization could occur due to the loss of cortical discriminatory processing. A shift in the circuit balance as a result of Au1 dysfunction may therefore contribute to PTSD and other anxiety disorders. In agreement, a recent study indicates that the shorter latency responses in LA neurons, evoked by direct thalamic inputs, contribute to the transition from cue-specific to generalized fear (Ghosh and Chattarji 2015). Our results highlight the importance of Au1 in behaviors relevant for survival and suggest that 
disorders of generalization may involve dysfunction in this cortical region.

\section{Acknowledgments}

Research reported in this publication was supported by NIMH grants to J.E.L. (R01 MH046516 and R01 MH038774). M.B.W was was supported by the Leiv Eiriksson mobility stipend (216761) from the Norwegian Research Council. We thank Claudia Farb and Sam Aviles for help with histology.

\section{References}

Aizenberg M, Mwilambwe-Tshilobo L, Briguglio JJ, Natan RG, Geffen MN. 2015. Bidirectional regulation of innate and learned behaviors that rely on frequency discrimination by cortical inhibitory neurons. PLOS Biol 13: e1002308.

Antunes R, Moita MA. 2010. Discriminative auditory fear learning requires both tuned and nontuned auditory pathways to the amygdala. J Neurosci 30: 9782-9787.

Armony JL, Servan-Schreiber D, Romanski LM, Cohen JD, LeDoux JE. 1997. Stimulus generalization of fear responses: effects of auditory cortex lesions in a computational model and in rats. Cereb Cortex 7: 157-165.

Bakin JS, Weinberger NM. 1990. Classical conditioning induces CS-specific receptive field plasticity in the auditory cortex of the guinea pig. Brain Res 536: 271-286.

Boatman JA, Kim JJ. 2006. A thalamo-cortico-amygdala pathway mediates auditory fear conditioning in the intact brain. Eur J Neurosci 24: 894-900.

Bowers ME, Ressler KJ. 2015. An overview of translationally informed treatments for posttraumatic stress disorder: animal models of pavlovian fear conditioning to human clinical trials. Biol Psychiatry 78: E15-E27.

Campeau S, Davis M. 1995. Involvement of subcortical and cortical afferents to the lateral nucleus of the amygdala in fear conditioning measured with fear-potentiated startle in rats trained concurrently with auditory and visual conditioned stimuli. J Neurosci 15: 2312-2327.

Cooke SF, Komorowski RW, Kaplan ES, Gavornik JP, Bear MF. 2015. Visual recognition memory, manifested as long-term habituation, requires synaptic plasticity in V1. Nat Neurosci 18: 262-271.

Edeline JM, Weinberger NM. 1993. Receptive field plasticity in the auditory cortex during frequency discrimination training: selective retuning independent of task difficulty. Behav Neurosci 107: 82-103.

Gao E, Suga N. 2000. Experience-dependent plasticity in the auditory cortex and the inferior colliculus of bats: role of the corticofugal system. Proc Natl Acad Sci 97: 8081-8086.

Ghosh S, Chattarji S. 2015. Neuronal encoding of the switch from specific to generalized fear. Nat Neurosci 18: 112-120.

Grosso A, Cambiaghi M, Concina G, Sacco T, Sacchetti B. 2015. Auditory cortex involvement in emotional learning and memory. Neuroscience 299: $45-55$

Jarrell TW, Gentile CG, Romanski LM, McCabe PM, Schneiderman N. 1987. Involvement of cortical and thalamic auditory regions in retention of differential bradycardiac conditioning to acoustic conditioned stimuli in rabbits. Brain Res 412: $285-294$.

Jovanovic T, Norrholm SD, Blanding NQ, Davis M, Duncan E, Bradley B, Ressler KJ. 2010a. Impaired fear inhibition is a biomarker of PTSD but not depression. Depress Anxiety 27: 244-251.

Jovanovic T, Norrholm SD, Blanding NQ, Phifer JE, Weiss T, Davis M, Duncan E, Bradley B, Ressler K. 2010b. Fear potentiation is associated with hypothalamic-pituitary-adrenal axis function in PTSD. Psychoneuroendocrinology 35: 846-857.

Jovanovic T, Ely T, Fani N, Glover EM, Gutman D, Tone EB, Norrholm SD, Bradley B, Ressler KJ. 2013. Reduced neural activation during an inhibition task is associated with impaired fear inhibition in a traumatized civilian sample. Cortex 49: 1884-1891.

Kholodar-Smith DB, Allen TA, Brown TH. 2008. Fear conditioning to discontinuous auditory cues requires perirhinal cortical function. Behav Neurosci 122: 1178-1185.
Kwon JT, Jhang J, Kim HS, Lee S, Han JH. 2012. Brain region-specific activity patterns after recent or remote memory retrieval of auditory conditioned fear. Learn Mem 19: 487-494.

LeDoux JE. 2000. Emotion circuits in the brain. Annu Rev Neurosci 23: $155-184$.

Letzkus JJ, Wolff SB, Meyer EM, Tovote P, Courtin J, Herry C, Luthi A. 2011. A disinhibitory microcircuit for associative fear learning in the auditory cortex. Nature 480: 331-335.

Maren S, Aharonov G, Stote DL, Fanselow MS. 1996. N-methyl-D-aspartate receptors in the basolateral amygdala are required for both acquisition and expression of conditional fear in rats. Behav Neurosci 110: $1365-1374$.

Masini CV, Babb JA, Nyhuis TJ, Day HE, Campeau S. 2012. Auditory cortex lesions do not disrupt habituation of HPA axis responses to repeated noise stress. Brain Res 1443: 18-26.

Milad MR, Rauch SL, Pitman RK, Quirk GJ. 2006. Fear extinction in rats: implications for human brain imaging and anxiety disorders. Biol Psychol 73: 61-71.

Milad MR, Pitman RK, Ellis CB, Gold AL, Shin LM, Lasko NB, Zeidan MA, Handwerger K, Orr SP, Rauch SL. 2009. Neurobiological basis of failure to recall extinction memory in posttraumatic stress disorder. Biol Psychiatry 66: 1075-1082.

Norrholm SD, Jovanovic T, Olin IW, Sands LA, Karapanou I, Bradley B, Ressler KJ. 2011. Fear extinction in traumatized civilians with posttraumatic stress disorder: relation to symptom severity. Biol Psychiatry 69: 556-563.

Ohl FW, Scheich H. 2004. Fallacies in behavioural interpretation of auditory cortex plasticity. Nat Rev Neurosci 5. 10.1038/nrn1366-c1

Ohl FW, Wetzel W, Wagner T, Rech A, Scheich H. 1999. Bilateral ablation of auditory cortex in Mongolian gerbil affects discrimination of frequency modulated tones but not of pure tones. Learn Mem 6: 347-362.

Pastalkova E, Serrano P, Pinkhasova D, Wallace E, Fenton AA, Sacktor TC. 2006. Storage of spatial information by the maintenance mechanism of LTP. Science 313: 1141-1144.

Paxinos G, Watson C. 2007. The rat brain in stereotaxic coordinates. Elsevier, London.

Romanski LM, LeDoux JE. 1992a. Bilateral destruction of neocortical and perirhinal projection targets of the acoustic thalamus does not disrupt auditory fear conditioning. Neurosci Lett 142: 228-232.

Romanski LM, LeDoux JE. 1992b. Equipotentiality of thalamo-amygdala and thalamo-cortico-amygdala circuits in auditory fear conditioning. J Neurosci 12: 4501-4509.

Sacco T, Sacchetti B. 2010. Role of secondary sensory cortices in emotional memory storage and retrieval in rats. Science 329: 649-656.

Schafe GE, LeDoux JE. 2000. Memory consolidation of auditory pavlovian fear conditioning requires protein synthesis and protein kinase $\mathrm{A}$ in the amygdala. J Neurosci 20: RC96.

Shema R, Sacktor TC, Dudai Y. 2007. Rapid erasure of long-term memory associations in the cortex by an inhibitor of PKM $\zeta$. Science 317: 951-953.

Teich AH, McCabe PM, Gentile CG, Jarrell TW, Winters RW, Liskowsky DR, Schneiderman N. 1988. Role of auditory cortex in the acquisition of differential heart rate conditioning. Physiol Behav 44: 405-412.

Volk LJ, Bachman JL, Johnson R, Yu Y, Huganir RL. 2013. PKM- $\zeta$ is not required for hippocampal synaptic plasticity, learning and memory. Nature 493: 420-423.

Weinberger NM. 2015. New perspectives on the auditory cortex: learning and memory. Handb Clin Neurol 129: 117-147.

Wilensky AE, Schafe GE, LeDoux JE. 1999. Functional inactivation of the amygdala before but not after auditory fear conditioning prevents memory formation. J Neurosci 19: RC48.

Xiong XR, Liang F, Zingg B, Ji XY, Ibrahim LA, Tao HW, Zhang LI. 2015. Auditory cortex controls sound-driven innate defense behaviour through corticofugal projections to inferior colliculus. Nat Commun 6: 7224 .

Znamenskiy P, Zador AM. 2013. Corticostriatal neurons in auditory cortex drive decisions during auditory discrimination. Nature 497: 482-485.

Received October 4, 2016; accepted in revised form October 24, 2016. 


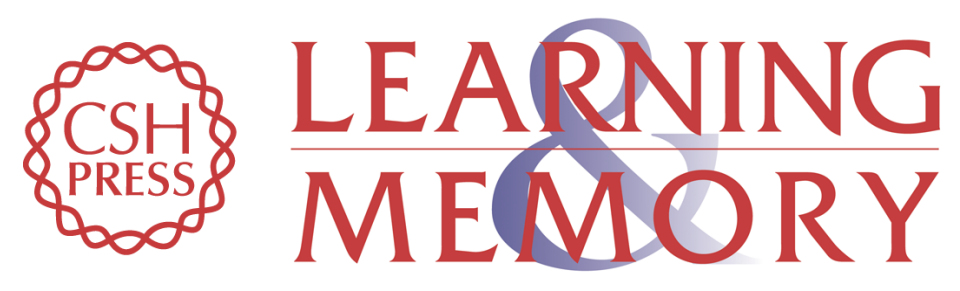

\section{Primary auditory cortex regulates threat memory specificity}

Mattis B. Wigestrand, Hillary C. Schiff, Marianne Fyhn, et al.

Learn. Mem. 2017, 24:

Access the most recent version at doi:10.1101//m.044362.116

Supplemental
Material http://learnmem.cshlp.org/content/suppl/2016/12/08/24.1.55.DC1

References This article cites 39 articles, 11 of which can be accessed free at: http://learnmem.cshlp.org/content/24/1/55.full.html\#ref-list-1

Creative This article is distributed exclusively by Cold Spring Harbor Laboratory Press for the Commons first 12 months after the full-issue publication date (see

License http://learnmem.cshlp.org/site/misc/terms.xhtml). After 12 months, it is available under a Creative Commons License (Attribution-NonCommercial 4.0 International), as described at http://creativecommons.org/licenses/by-nc/4.0/.

Email Alerting Receive free email alerts when new articles cite this article - sign up in the box at the Service top right corner of the article or click here. 